\title{
Arbor
}

\section{La dimensión pública de la fe}

\author{
Joaquín García Roca
}

Arbor CLXXI, 676 (Abril), 719-743 pp.

La compleja trayectoria que, mediante ruptura o compromiso, configura la relación entre la esfera pública y la privada, ha definido una nueva manera de concebir, vivir y preservar la realización de lo religioso en el mundo. Para delimitar el campo de estudio se establecen tres usos de la dicotomía "público-privado». Es posible establecer de este modo la triple dimensión del espacio en que reciprocamente se determinan. El cristiano encuentra razones suficientes en su propia tradición para reclamar, exigir y fomentar la distinción entre ambos territorios.

La compleja trayectoria que, mediante ruptura o compromiso, configura la relación entre la esfera pública y la esfera de la existencia priva$\mathrm{da}$, ha definido una nueva manera de concebir, vivir y preservar la realización de la fe y la figura de la Iglesia.

Cualquiera que sea el origen de la distinción y el momento de su nacimiento, la diferencia entre lo público y lo privado persigue a la reflexión actual con la fuerza de una pesadilla. La dicotomía público-privado se ha impuesto como categoría básica del pensamiento jurídico (derecho privado y derecho público), determina la índole de los intereses en la vida colectiva (interés público y privado), expresa la forma en que los individuos regulan sus relaciones (atentos al público o al privado) y, finalmente, se ha convertido en un criterio para interpretar los acontecimientos (historia de la vida privada). El proceso de creación de ambos territorios no ha sido lineal, regular y unívoco. Los límites entre ambos son difusos, ya que dependen de las latitudes geográficas, de las prácticas sociales, del régimen político constitucional y de aquello que en cada momento se considera administrable. 
La dimensión pública del proyecto de vida inspirado en el Evangelio de Jesús de Nazaret es decisiva para que la Iglesia Católica no malogre su misión en el momento histórico actual (BELDA: 53) y constituye la prueba decisiva que marca hoy la diferencia entre los distintos modelos de Iglesia.

Para delimitar, representar y ordenar el campo de investigación estableceremos tres usos de la dicotomía «público/privado» que pueden iluminar la realidad y demostrar su idoneidad en la problemática actual. Es posible establecer de este modo la triple dimensión del espacio en que recíprocamente se determinan lo público y lo privado en su carácter dinámico y en su contraste.

1. Hay un área particular, netamente delimitada, que hace referencia a esa parte de la existencia identificada como privada, una zona de inmunidad ofrecida al repliegue, al retiro, donde uno puede abandonar las armas y las defensas de las que le conviene hallarse provisto cuando se aventura en el espacio público; donde uno se distiende, donde uno se encuentra a gusto, «en zapatillas», libre del caparazón con que nos mostramos y nos protegemos del exterior. Es el lugar familiar y doméstico (DUBY: 10).

Lo público se distingue de lo privado como se contrapone el mundo sistémico al mundo de vida, que es el ámbito de las relaciones interindividuales, el espacio de lo íntimo y familiar, el lugar de la interacción cotidiana y de lo irreductiblemente personal. El mundo sistémico, por el contrario, evoca la organización estructural, la coacción institucional y la sociedad anónima y administrada. A un lado, un remanso de paz, refugio familiar en que se eligen amistades y libertades; al otro, las imposiciones de la vida pública, la disciplina del trabajo jerarquizado, el rigor de los compromisos. Esta dicotomía valora los encantos del terreno reservado, incesantemente amenazado por la fatal intrusión de las exigencias públicas (CASTAN: 413).

2. El espacio público se caracteriza por estar abierto al espectador, frente al espacio privado que se caracteriza por estar escondido. Si lo primero está presidido por la publicidad, lo privado es amigo del secreto. La accesibilidad es la nota de lo público. «En lo privado se encuentra encerrado lo que sólo le pertenece a uno mismo, lo que no concierne a los demás, lo que no cabe divulgar ni mostrar... La vida privada se muestra, pues, como tapiada» (DUBY: 10). El espacio público está directamente basado en el uso público de la razón, que llega a introducir la discusión y el consenso, amplía la exigencia de la crítica racional a los terrenos que hasta entonces se habían sustraído al debate público y pretende hablar en nombre de la opinión pública constituida, frente a la política del príncipe (CHARTIER: 24). 


\section{La dimensión pública de la fe}

3. El espacio público es el territorio de lo generalizable y universalizable. Está en relación con el interés colectivo y tiene una pretensión de universalidad. En esta concepción, lo público es el Estado, el territorio de la Administración; y, por otra parte, " lo privado correspondía a todo lo que se sustraía al Estado» (ARIES: 17), al territorio particular acotado en razón de lazos de procedencia y sangre, o simplemente de intereses particulares. Lo privado es aquello que resulta excluyente, y viene de «privar», que significa también negar a los demás lo que uno tiene, y por eso es privada especialmente la propiedad.

\section{Fe y mundo vital}

La fe cristiana tiene la fisiología propia de la convicción que la hace anidar en el mundo vital de cada persona. Allí crece o se achica, allí se gana o se pierde. Hasta tal punto se identifica con él que resulta imposible saber si la fe habita en el mundo vital o más bien, lo constituye. Es su auténtico escenario no sólo como espacio donde se ubica, sino como elemento constitutivo de su representación.

El mundo vital es la esfera de lo íntimo y familiar, de la producción de sentido, de la normatividad autónoma, de la subjetividad. Constituye el ámbito de las relaciones intersubjetivas que preceden y acompañan a la reproducción de la vida humana; las comunicaciones reales y simbólicas entre un número reducido de personas forman la red de intimidad, familiaridad, amistad e interacción cotidiana. Como ha señalado HABERMAS, los mundos vitales son a la vez el laboratorio de las experiencias fundamentales, el árbitro del sentido y el experimento de las legitimaciones. De este modo, el mundo vital se constituye en el lugar de las experiencias fundamentales, que configuran la identidad personal. Desde la vivencia de la temporalidad hasta la creación del «nosotros» se fraguan y moldean en aquel escenario, que forma «el reino de las evidencias originarias».

En contraposición al mundo vital unas veces, colonizándolo otras, y yuxtapuesto las más, aparece el territorio del sistema social como el mundo de lo anónimo, de la organización estructural, de la normatividad heterónoma y de la coacción institucional. Constituye el conjunto de relaciones sociales tipificadas, de tramas normativas y estructuras de control que generan finalmente una sociedad administrada. Circulan por sus nervios la eficacia, el dinero y el poder.

Si atendemos a esta primera delimitación entre lo público y lo privado que significa el mundo de la vida (privado) y el sistema social (públi- 
co), la fe pertenece inequívocamente a la esfera de la privaticidad, de la intimidad y de la familiaridad, de las relaciones intersubjetivas y de la producción de sentido. De ellas recibe sus providencias.

Aunque sean muchas las patologías que la privatización de la fe haya causado en los últimos años, no podemos ignorar su fisiología: la fe pertenece, en todo su rigor, al mundo de la vida. En consecuencia, la forma pública de la fe tiene en su propio origen la marca y el relieve propios de las convicciones profundas, que se fraguan en la conciencia y en la intimidad. La presencia pública de la fe no puede ignorar este hecho si quiere distanciarse de la mera propaganda o de la simple publicidad. Será necesario hoy reivindicar:

- La vida cotidiana como espacio primordial de la realización de la fe.

- La conciencia como vehículo originario de la fe.

- El misterio como cualidad de su presencia.

\section{La vida cotidiana}

El auténtico timbre de la fe, que deriva de la unión con Dios como presencia viva y escondida en el corazón del hombre, repercute con toda la gama de sonidos en el escenario de la vida cotidiana, que está hecha de encuentros y de ocasiones, de conversaciones y de desencuentros, de ceremonias y de acontecimientos. Todo ello es la nervatura por donde circula la savia de la fe, su primera y decisiva ubicación.

Hay que recuperar este escenario de lo cotidiano como la trama por antonomasia de la fe, y desdramatizar la teología de la fe hecha primariamente de situaciones extremas, que han impuesto a la representación de la fe un timbre trágico y grandilocuente, como si la excepción pudiera definir la realidad misma. El marco habitual de la fe era sustituido por la situación excepcional; en lugar de rastrearla por los residuos cotidianos, se buscaba en los lugares insólitos y extraordinarios.

La dimensión pública de la fe era pensada desde los rasgos de la conversión, cuando en realidad los episodios de la vida diaria son los lugares mismos de la fe y la vida cotidiana es el tejido conjuntivo de la gracia (GARCía RocA, 1988: 414). Si la vida diaria es el marco de la fe, la presencia pública es inseparable de los rasgos esenciales de lo cotidiano. Subrayaré aquellos que son decisivos en la hora actual.

La cualidad primaria de lo cotidiano es su precariedad y su latencia. Todo en ello parece tan obvio, que invita a confundirse con lo natural. Es el lugar de lo imperceptible, de las interacciones tan triviales y habituadas, que GofFman identificó como el «polvo» de la actividad social. Sus 
manifestaciones se construyen con material frágil e inestable, y todo en ello es latente y lábil, y a través suyo circula lo obvio y lo informal metamorfoseado de convicción y de rituales.

La vida cotidiana es una especie de tejido, que sostiene las interacciones y los modos de significar habituales en nosotros, así como regula constantemente las relaciones sociales. Por esta razón se ha considerado como unidad fundamental de la vida social (WoLF: 23). El Sínodo de Obispos sobre los Laicos ha visto en ella el territorio natural de la fe, en cuanto expresa «la unidad de vida» $\mathrm{y}$ «la concretez en condiciones cotidianas y seculares» (Proposición 5).

Es el laboratorio donde se experimenta la identidad, la dignidad, el desconcierto, las reservas, los valores, los olvidos y los comportamientos apropiados. Es allí donde, si fuera necesario, reconstruye una nueva definición de su propio ser y aprende a producir nuestro sentido de la realidad y de la lealtad. Por esta razón, nada hay irrelevante en la vida cotidiana, y es «en los acontecimientos cotidianos donde se muestra la fidelidad al Espíritu Santo y se realiza la nueva ley de la caridad» (Proposición 5).

Como quería ORTEGA Y GASSET, «la vida es andar a golpes y caricias con las cosas». Si fuera sólo caricias, sería demasiado frágil; si sólo conociera los golpes, sería el lugar de lo inerte. Es a la vez lo que hacemos y lo que nos pasa, actividad y pasividad, institución y espontaneidad.

Si la presencia de la fe tomara radicalmente en serio su ubicación en la vida cotidiana, debería incorporar con rigor lo que la tradición llamó «actus signatus» $\mathrm{y}$ «actus exercitus», es decir, el acto directo y el acto reflexivo. La reciente historia de Occidente sobredimensionó la importancia de la reflexión y de la autoconciencia hasta disminuir la importancia de lo inmediato y de lo vivido.

Frente a este dominio de la reflexión, la fenomenología empezó a mostrar que hay un modo de ser en el mundo que no está ha sometido a nuestro arbitrio y que posee una autoridad originaria y una pretensión inmediata de verdad. En este supuesto, la reflexión acompaña simultáneamente al decir, es «el acto directo» de los escolásticos. GADAMER recuerda, en distintos lugares de su obra, el gran descubrimiento que se produjo en filosofía cuando HEIDEGGER utilizó esta distinción escolástica: «Nos pareció un camino hacia la libertad, ya que prometía la liberación del cerco inevitablemente limitativo de la reflexión». Hay un acto directo e inmediato en el cual se experimenta la realidad de manera completamente noreflexiva, y sólo se transforma en un «actus signatus» a costa de un nuevo ocultamiento.

Desarrollar la pretensión del acto directo e inmediato frente al predominio de la reflexión ha sido una de las tareas primordiales de la Nue- 
va Hermenéutica que GADAMER se ha propuesto mostrar en el ámbito de la experiencia artística y en la experiencia histórica.

Fue precisamente Dietrich BONHOEFFER, el teólogo que en el siglo XX ha llevado la reflexión a mayores alturas, quien vio la importancia de la distinción. Vio en la fe un acto directo e inmediato cuya centralidad determina todas sus dimensiones. La presencia pública de la fe tiene la forma propia del acto directo e inmediato y, como tal, transita «por un universo sin textos ni escrituras» (LE GoFF: 144).

Es un mérito indiscutible de la Teología de la Liberación haber reivindicado la dimensión experiencial de la fe como acto primero; lo cual permite declarar el resto como acto segundo y derivado. Sólo la espiritualidad -acto primero y directo- legitima la teología.

\section{Reivindicación de la conciencia}

Todo lo que afecta radicalmente al hombre le atañe a través de la conciencia. Como ha recordado ROviRA, «el lugar de la fe es la conciencia del hombre. Conciencia inteligente y libre, que señala ese punto donde el hombre se sabe persona, es decir, individuo en relación con los otros. Ese punto central desde el cual el hombre juzga, decide, se adhiere y se compromete. Allí donde se experimenta a sí mismo abierto y capaz de trascender todo conocimiento y toda acción puntuales. Allí donde se sabe también trascendido por la Palabra y por el Amor» (1988: 23).

Si éste es su lugar, la conciencia impone a la fe su modo de ser y sus características peculiares. Quisiera subrayar aquellas que determinan importantes consecuencias para la presencia pública. Con frecuencia, en el campo de la moral se ha afirmado que la ley de Dios tiene una realidad en sí misma, y se representa como algo extrínseco a la conciencia. Este extrínseco fue rechazado por el Concilio Vaticano II al afirmar que corresponde a la conciencia «inscribir la ley divina en la sociedad terrestre» (GAUDIUM ET SPES 36, 2). No existe ninguna otra vinculación entre la ley de Dios y la realidad humana. La ley de Dios no está inscrita en las cosas ni en la naturaleza, como quería el tradicionalismo católico, sino que corresponde al hombre descifrarla a través del discernimiento y de la formación de la conciencia. La solución concreta e inmediata no puede dictarse desde fuera. Se puede, evidentemente, recordar o establecer un cuerpo de doctrina; pero en ningún caso puede sustituir al acto moral que nace cuando la ley de Dios se encuentra con la realidad a través de la conciencia. Los llamados «primeros principios, con toda su validez autónoma, quedan a gran distancia de la acción ética»; la conciencia cubre aque- 


\section{La dimensión pública de la fe}

lla distancia en referencia a la concreción existencial, hasta producir «una mutua influencia entre los valores fundamentales y la experiencia ética existencial» (SANCHIS: 78). La generación del Concilio entendió este hecho como la gran novedad y se dedicó a promocionar la conciencia, a responsabilizarla, ya que sólo ella puede ordenar la realidad según Dios.

Se comprende bien que la teología anticonciliar arremeta contra esta verdad, ya que en ella está el auténtico giro que supuso el Vaticano II. En la clausura del Encuentro que celebraba el veinte aniversario de la Humanae Vitae, el teólogo papal C. CAFARRA identificaba a los teólogos «adversarios» como aquellos que enseñan que «la libertad del hombre, la conciencia, la comprensión de sí mismo, es el hecho originario, último, fundamental y fundante de toda la historia humana, para los cuales es ilícito apelar a una realidad (Dios) que precede a la conciencia del hombre» (HÄRING: 224, nota 89).

Si la fe anida en la conciencia, hereda de ella aquellos rasgos que le son consustanciales. La conciencia como centro de la decisión y del juicio está hermanada con la intimidad. Con frecuencia le acompaña el drama íntimo, y no pocas veces conoce la soledad y el desgarro. Todo aquello que afecta al hombre en su ultimidad va acompañado de discreción.

La conciencia en la profesión de fe tiene más derechos que los que estamos dispuestos a concederle. No es legítimo confundir lo que es una expresión de la intimidad con la tendencia a la privatización de la fe; más bien será necesario redescubrir el papel esencial de la fe en la constitución del fuero interno.

Se ha observado con razón que las nuevas formas de religión fueron un factor decisivo en el origen de la esfera privada: la piedad interior, el examen de conciencia, la confesión individual, la dirección espiritual, la meditación (ARIES: 10). Las dos Reformas del siglo XVI -la protestante y la católica- estimaron una piedad que cada vez fue interiorizándose más, y de este modo modificaron la idea de uno mismo y de su papel en la vida diaria de la sociedad (LEBRUN: III).

La fe no puede renunciar a su vinculación con la intimidad ni abandonar su protección ante la mirada de los demás. El acto de fe nace allí donde el individuo deja de insertarse en solidaridades orgánicas y de vincularse en linajes, ya que la fe no viene de la sangre. El creyente no puede ser absorbido por nada, ni siquiera por la comunidad. La fe es lo más íntimo, porque es lo más libre. La comunidad que nazca de este hecho original es una comunidad de hombres libres.

La presencia pública de la fe no puede significar el dominio de los vínculos comunitarios sobre la realidad de la conciencia, sino que la expresión comunitaria de la fe posibilita el cultivo de la conciencia, la alimen- 
ta y la sostiene. Ninguna legislación eclesiástica puede ser insensible a este hecho.

Durante toda la historia del cristianismo se da una dialéctica entre religión personal y religión colectiva. Desde su fundación, el cristianismo aparece dividido entre dos tendencias aparentemente irreconciliables. Es, a la vez, una religión eminentemente personal que llama a cada cual, con individualidad, a la conversión, a la fe y a la salvación, y una religión colectiva que se despliega en Iglesia y expresión comunitaria. Estos dos factores se han roto con frecuencia y hemos asistido a continuos bamboleos.

Es necesario modificar los indicadores de la fe y del testimonio. Cuando se valora el hecho radical de la conciencia no es posible medir el interés por el hecho religioso - y, en consecuencia, la desafección religiosaa través de las formas típicas de vinculación existentes en la sociedad tradicional ni por la adhesión explícita a la organización ni por las expresiones del sentimiento religioso. La presencia de la fe y la dinámica religiosa deben perseguirse por otros medios.

\section{La disciplina del Misterio}

La fe como participación en la Pasión de Dios en esta tierra posee un aspecto cultual y mistérico que excluye a los no iniciados. La primitiva praxis cristiana diferenciaba en la celebración de la fe aquella parte a la que podían acceder todos y aquella otra que estaba reservada a los iniciados («disciplina del arcano»).

Ha sido precisamente el teólogo de la mundanidad, que negó cualquier repliegue del cristiano ante el mundo, quien ha afirmado con mayor radicalidad la necesidad de «proteger de la profanación los misterios cle la fe cristiana» (BONHOEFFER: 185).

Para BONHOEFFER, «la disciplina del arcano era el contrapunto necesario del tema de la interpretación no religiosa» (BETHGE: 1189). Cuanto más entrevió la necesidad de un compromiso secular, tanto más comprendió el papel de la comunidad reunida en el servicio religioso, la oración, la alabanza, la meditación y el «culto auténtico». Este aspecto de la fe es «arcanum» en la medida misma en que los fenómenos básicos de la vida no se adaptan a las demostraciones propias de una misión ni pueden instrumentalizarse en función de otra cosa. El Evangelio se aviene mal con la propaganda y con los procedimientos artificiales. Los misterios de la fe pierden su sentido cuando se ofrecen inmotivadamente y se distribuyen a cualquier precio. De este modo, la disciplina del arcano de- 
fiende al mundo de la coacción religiosa, y es precisamente esa disciplina la que libra a la fe de la trivialidad. La presencia pública de la fe debe mantenerse unida a la disciplina del arcano. «Sin mundanidad, la disciplina del arcano es ghetto, y la mundanidad sin disciplina del arcano es únicamente boulevard» (BETHGE: 1192).

Cuando hay hombres que leen la Escritura, parten el pan, cantan e invocan e interrogan los símbolos de la tradición, realizan la primera estación en el camino de la presencia pública de la fe.

El sentido profundo de la disciplina del arcano le hizo comprender a BONHOEFFER que «la Iglesia sólo puede cantar gregoriano si al mismo tiempo clama en favor de judíos y comunistas». Como testifica el médico del campo de concentración, "por la puerta entreabierta de una habitación de las barracas, antes de quitarse los trajes de prisionero, vi al pastor BoNHOEFFER de rodillas, en ferviente oración con su Dios. En el lugar mismo de la ejecución elevó también una corta plegaria, y después subió valerosa y serenamente la escalera del patíbulo. No creo haber visto nunca morir a un hombre con tanta confianza en Dios» (ZAHRNT: 191).

Articular la oración como hecho personal y la confianza en Dios como hecho público es lo único que puede salvar la dimensión pública de la fe de cuantas profanaciones padece hoy. Cuando nos empeñamos a través de la TV en arrancar testimonios como si de cronología se tratara, siento como si mi condición de testigo se tambaleara. Cuando veo una Eucaristía en un estadio de fútbol, siento cómo se transgrede la conmemoración de Aquél a quien se celebra en la liturgia, ya que allí se cruzan los afectos con los silencios, la mirada con el canto, la soledad con la compañía.

Hoy seguimos sin descubrir lo que BoNHOEFFER llamaba «arcani disciplina», que era para él la condición indispensable de la inmersión del cristiano en el compromiso terrestre, esa autonomía de la fe que segrega al profano, al diletante y al amateur (ÁlvAREz BoLADO: 200).

\section{Fe y espacio público}

El carácter de la fe se ilumina igualmente en el interior del dilema entre abierto y cerrado, oculto y manifiesto. El espacio público es el lugar abierto al público, que se realiza frente a espectadores. Su carácter manifiesto marca la delimitación ante aquello que es privado y oculto. Lo abierto e ilimitado frente a lo cerrado y limitado. Lo público implica visibilidad, transparencia y comunicabilidad.

Es privado aquello que se esconde del público y no está controlado por él. Mientras lo primero está presidido por la publicidad, lo segundo lo 
está por el secreto. Lo privado es un ámbito de oscuridad y de reserva. El secreto es una condición de la vida privada. El espacio público es de libre acceso; el espacio privado, por el contrario, supedita el acceso a determinadas condiciones discrecionales. En la esfera pública, la información está disponible y también el acceso a ella; en la esfera privada, la información y su acceso están reservados.

La fe pertenece, de este modo, al espacio público que nace de la comunicación, del debate y de la participación con sus respectivas providencias.

\section{Rehabilitación de la comunicación}

La fe pertenece al género comunicacional en razón de su origen y de su misión. Nace de la Palabra, y todo en ella está orientado a su transmisión. La Palabra y la Misión le confieren una estructura lingüística cuyo sentido se realiza en la comunicación: todo en ella es comunicable y existe para ser entregado.

La comunicación es significativa en nuestro tiempo cuando puede acreditarse a través de la palabra libre, la información y el entendimiento. El origen del espacio público está unido al ejercicio de la palabra libre. El habitante de aquel espacio es el ciudadano cuyo nacimiento estuvo (y cuyo destino está) unido al uso público de la palabra.

Donde no hay palabra libre no cabe esfera pública; por eso las dictaduras son la negación de la publicidad, en la medida en que retiran la palabra y la ponen bajo cautela. Cuando la palabra no es ley, sino capricho, el espacio social se privatiza. El secreto es el lugar natural de la ar cracia, así como la palabra pública, la prensa libre y las discusiones lamentarias son el universo propio de la democracia moderna (URB. 88).

La palabra libre es el órgano exploratorio de la verdad polifóni. Cuando desaparece su ejercicio crecen las consignas, las orientaciones unilaterales y las sospechas infundadas. Se convierten en moneda corriente la admiración incondicional al jefe y la servidumbre de la uniformidad, ya que el grupo humano que no celebra la diferencia y el pluralismo acaba concentrando el poder, alimentando las calumnias y renunciando a la conversión.

Vivimos la tentación de buscar más la lengua común al modo de Babel que la diversidad al modo de Pentecostés. y todos sabemos cuál es el destino de Babel: recitar la misma canción, vestir el mismo uniforme, imponer la misma música. Babel no tuvo futuro. Será necesario reivindicar 


\section{La dimensión pública de la fe}

la utopía de Pentecostés, que traerá de nuevo a la Iglesia la voz necesaria de Leonardo BofF y el recuerdo santificado de Monseñor ROMERO.

Hay una posición, que hace suya la libertad como instrumento de análisis, principio de independencia y medio de transformación, que recuerda el principio de toda tragedia. Se asemeja al destino trágico de una madre que no se reconoce como madre porque su verdadera aspiración era trascendente y mística, o no reconoce a sus hijos porque no nacieron con sus marcas o no siguen sus planes.

La práctica comunicativa que exige la condición pública de la fe se acredita en el ejercicio de la información, tanto en su interior como hacia fuera. El espacio público no tiene secretos ni sustrae información. El secreto no puede confundirse con el Misterio, ni éste se identifica con lo esotérico. La auditora laica Albina ASPELL afirmaba en el Sínodo sobre los Laicos, que «una libre circulación de información tiene el poder de evitar los problemas, acabar con los chismes y cancelar las sospechas».

Cuando desde diferentes instancias se solicita transparencia informativa en la Iglesia, no se hace más que realizar su presencia pública. Si los cristianos se interesan por la elección de sus pastores y quieren librarla del secretismo de sus finanzas, están realizándola como presencia pública. A nadie puede sorprender que grupos cristianos escriban al Papa interesándose por el pastor que regirá los destinos de la diócesis. Lo que ayuda a realizar una nota sustancial de la Iglesia no puede ser temido por nadie. No parece que los acontecimientos marquen esta dirección.

En tercer lugar, la práctica comunicativa está orientada al entendimiento, que obliga a «inculturar» y a dar razón. La Iglesia tiene una pretensión de catolicidad que realiza mediante la inculturación. Para alcanzarlo no basta con compartir el lenguaje, sino que es necesario asumir la fuente misma de la racionalidad cultural, que ciertamente no puede confundirse con una determinada racionalidad científica o filosófica, pero tampoco puede identificarse con la mera retórica o el simple fundamentalismo. Construir instancias razonables, que sean comunicables e inteligibles hoy, es una exigencia de la presencia pública, que, sin dejar de respetar los ámbitos autónomos del saber, ha de atender a los criterios de la argumentación.

Si esto no se lograra, nos encontraríamos con un ejercicio autorreferencial que, además de inmunizar a la fe contra toda interpretación que quiera competir con ella, abocaría a graves y serios peligros para la convivencia. La vigencia del fundamentalismo ha puesto tristemente de actualidad este principio. Sólo aquella Iglesia capaz de ofrecer referencias válidas a quienes ni reconozcan su autoridad ni cierren la cuestión con la simple invocación al Libro podrá acreditarse como presencia pública. 
El desprecio intelectual que se observa en muchos grupos religiosos y la inflación de los climas irracionales no ayudarán en esta tarea, sino que más bien reforzarán la privatización de la fe. La condición pública de la Iglesia necesita rehabilitar el concepto de razón, que, como advierte HABERMAS, "ha de cuidarse muy bien por ambos lados: ha de guardarse de volver a caer en las trampas del pensamiento centrado en el sujeto, que culmina en la razón instrumental y convierte en objeto todo cuanto le rodea, incluso a sí mismo, y también de los rasgos totalizantes de una razón inclusiva que todo se lo incorpora y, al final, acaba triunfando como unidad sobre toda diferencia».

Rehabilitar la razón es un imperativo de la condición pública de la fe y de la Iglesia. Esta rehabilitación llevará a recorrer caminos inusitados. Se abrirá el diálogo con la ciencia desde el supuesto de que «uno de los indicadores de la vitalidad de la Iglesia a lo largo de su historia ha sido su aptitud para instaurar un diálogo y una confrontación crítica con las cosmovisiones dominantes» (RUIZ DE LA PEÑA: 217); o se apostará, según la sugerente y entusiasta propuesta de GÓMEz CAFFARENA, por «la asimilación de la crítica en forma fecunda autocrítica, desde la que quepa después honestamente criticar todas las otras instancias culturales», y se fomentará «la búsqueda honrada de la verdad donde quiera que pueda estar, sabiendo que la verdad cristiana no sólo no habrá perdido, sino que saldrá depurada y enriquecida» (61 y 67).

\section{El debate público}

Una presencia pública es significativa cuando se somete al debate abierto y al diálogo permanente. No existe en la sociedad moderna ningún espacio que pueda ser sustraído a la crítica ni ninguna cuestión que esté reservada a determinados clientes. La fe y la Iglesia son públicas cuando aceptan la crítica y la ejercen tanto hacia dentro como hacia fuera. El debate y la participación no es sólo un instrumento disponible para conseguir la publicidad, sino aquel acontecimiento que dispone la más alta posibilidad de su realización.

No son soluciones válidas ni la marginalidad, que nos reduce al exclusivo espacio religioso, ni la privatización, que nos reduce al exclusivo espacio íntimo, ni la prepotencia, que se practica desde la imposición.

La presencia pública de la fe implica una sociedad en búsqueda y en deliberación. En el interior del territorio de la historia y en una sociedad compleja adquieren consistencia y relevancia la autorreflexión y el debate ante la diversidad de culturas, ante la pluralidad de perspectivas. Y, 
en consecuencia, se hace imposible la unanimidad de prácticas y la homogeneidad de comportamientos. La búsqueda de finalidades y de significaciones está sometida a un proceso inacabado, al diálogo y a la discusión. A la idea de «publicidad» le resulta consustancial la crítica, aun cuando la ejerza contra ella misma.

El debate público sólo es posible cuando los interlocutores son conscientes de que llevan algo valioso que merece ser propuesto. El debate se opone al silencio, a la complicidad o a la indiferencia. Cuando se identifica la crítica con la disolución de la identidad o con el debilitamiento de la institución, se comete un grave error. La presencia del debate es síntoma de salud. La carta que los teólogos dirigen al Papa advirtiendo de «graves y peligrosas violaciones de la libertad de investigación, excesos improcedentes en sus competencias, abuso de poder...» es un ejercicio de la dimensión pública de la fe. El debate abierto por los teólogos europeos ha hecho más por la credibilidad de la Iglesia que aquellos silencios que, con frecuencia, sólo indican indiferencia, miedo o adulación.

Frente al silencio de los acobardados, frente a las complicidades de los aduladores, frente a la indiferencia de los tibios, el debate da por supuesta la existencia de unas convicciones capaces de dar sentido y esperanza para la vida. Sólo una identidad abierta a la riqueza de la realidad y a la interculturalidad puede albergar una convicción firme. El espacio público reclama que cada cual diga su palabra. No debemos faltar a la cita, con una palabra propia en aquellas cuestiones en que la tengamos, con el silencio allí donde sea necesario y con la búsqueda compartida allí donde sólo se pueda compartir la duda. Cuando se renuncia a decir la palabra única, se descubre lo importante que es no dejar de decir la palabra necesaria.

Cuando no sucede así, la convicción es sustituida por la intransigencia, el testimonio vital por la provocación y la adhesión a la autoridad se reduce a aquello que confirma los prejuicios propios y los privilegios del propio grupo. Lo que no está abierto al debate muestra su propia debilidad interna.

El ejercicio del debate público se sustenta sobre unas condiciones, que lo posibilitan y lo alimentan. Carece de sentido el ejercicio del diálogo si no se reconoce en el otro a un auténtico interlocutor con el que es posible alcanzar acuerdos a través del ejercicio supremo del debate. Con frecuencia se olvida que el objetivo último del diálogo no es ejercer la virtud heroica de la comprensión y de la tolerancia, sino realizar la posibilidad misma de la verdad a través de los acuerdos. La verdad está abierta al acuerdo intercultural; y, si no lo estuviera, sería signo de su debilidad.

Carece de sentido el acuerdo cuando las partes concurrentes no están dispuestas a la transacción. Pero no a la transacción que viene de la sim- 
ple negociación estratégica, sino a la transacción que viene de la profundización en la realidad, ya que el pluralismo es la forma humana de alcanzar la verdad.

Como espacio público, la Iglesia está llamada al ejercicio del consenso y del acuerdo. Carece de sentido querer hacer propuestas significativas en el orden moral que se sitúen más allá del diálogo y de la transacción. La pretensión de validez es inseparable de la incorporación del contexto y de la implicación en un mundo intersubjetivo compartido. El concepto hermenéutico de «fusión de horizontes» (Gadamer) es apropiado para interpretar lo que acontece en todo diálogo.

La calidad del diálogo en la Iglesia es el indicador de su salud pública. Por esta razón, la Conferencia de obispos suizos pedía para la Iglesia proseguir el espíritu de la Ecclesiam Suam de Pablo VI: «El diálogo es el mejor medio para expresar la comunión, la participación y la cohesión de todos... La noción de consultivo y de deliberativo no respeta plenamente la naturaleza propia de la Iglesia».

La dimensión pública de la fe sabe articular la convicción cristiana con el diálogo y se opone a cualquier desencuentro entre diálogo y verdad. Con la misma firmeza con que defiende el pluralismo y la tolerancia, se opone al dogmatismo y hace cuerpo con la democracia. Vivir en la laicidad significa apostar por una sociedad abierta, en la que la verdad, la justicia y el derecho no están nunca de una sola parte. De ahí que el creyente salga de sus propios territorios y transite en compañía otros paisajes con humildad. Abierto a la verdad que viene también de fuera, no renuncia a investigar y a dialogar con otras tradiciones. Abierto a la justicia que viene también de otra parte, construye la ciudad con materiales comunes. Abierto al derecho, se bate con otros para que esta historia nuestra sea más rica. El cristiano ha de descubrir las finalidades sociales a través de la reflexión y el diálogo, en búsqueda constante de sus fundamentos, al tiempo que amplía progresivamente el contenido y el alcance de lo valioso.

\section{Reivindicación de la participación}

La comunicación y el debate han originado un sentido de lo público que equivale al ejercicio de la participación. Los pueblos organizan su convivencia a través de la formación de la voluntad colectiva. La instancia única e inapelable para la organización de la convivencia ha perdido vigencia social y pertinencia teórica. El interés público se determina a través de la búsqueda común de finalidades. Al cristiano no se le exime 


\section{La dimensión pública de la fe}

de esta responsabilidad; más bien añade nuevas motivaciones para la participación.

El Concilio Vaticano II reconoció como positiva esta «reivindicación de los hombres de nuestro tiempo» (Gaudium et Spes, 36, 2) y reivindicó la búsqueda incesante de la voluntad de Dios y la necesidad de descifrarla a través de instrumentos humanos. Tan importante es el papel de la propia búsqueda que resulta inútil e improcedente que los pastores «den soluciones concretas e inmediatas a los problemas». El Concilio estableció igualmente el parentesco entre el cristianismo y la democracia, y afirmó, como vio lúcidamente $K$. RAHNER, que la voluntad democrática inauguraba una dinámica positiva para la propia Iglesia.

Los Padres conciliares eran conscientes de que, al renunciar al fundamento único de la sociedad, se abría una espoleta hacia el vacío moral, hacia la inestabilidad social y hacia la fragilidad personal. No obstante, se resistieron a pensar que el destino de la fe estuviera en lograr una hegemonía social ni una sociedad cerrada.

La condición pública de la fe es otra manera de afirmar la ciudadanía del creyente. El primer itinerario hacia «la publicidad de la fe» es la colaboración responsable en la construcción de la convivencia y en el destino colectivo. Sin protagonismos, colaboramos en la vida de los barrios, alentamos la comunicación, compartimos el dolor de los sufrientes, acompañamos los procesos educativos, impulsamos la cooperación internacional y alertamos de la necesidad de un nuevo orden junto a tantos que lo reclaman... La participación marca la altura de la «publicidad de la fe».

Sólo con la participación podremos dinamizar la utopía mayor de estos últimos años, que nos ha convertido en ciudadanos; y cuando alguien se convierte en ciudadano, ya no es posible sustraerle ningún espacio de realidad. Un ciudadano-trabajador no tiene por qué dejar sus derechos constitucionales a la puerta de la empresa, sino que necesitará vitalmente la democratización del trabajo y de sus beneficios. ¿Hay alguna razón para que esto deje de ser válido en el espacio de la Iglesia? Más bien creo que hay razones adicionales para lo contrario, ya que la dinámica del poder tiende a su concentración y la dinámica de la fe pretende disolverlo.

Únicamente se entra en los caminos liberadores del Concilio Vaticano II cuando se descubre que nadie puede reivindicar de manera exclusiva la autoridad en la Iglesia. Nadie puede identificarse absolutamente con la autoridad de Jesús ni reducirla a una sola expresión. La causa de Jesús sólo va adelante si se la empuja desde distintas instancias. Existe la autoridad de la comunidad, tan importante como la del Magisterio; existe la autoridad del teólogo, tan necesaria como la del obispo. ¿Quién 
podrá despreciar la autoridad del profeta, o qué jerarca está legitimado para hacerle a Pedro Casaldáliga «serias advertencias»? En la Iglesia no hay poder, sino autoridades. Absolutizar cualquiera de ellas equivale a impedir el movimiento de conversión.

La exaltación de los líderes por encima de sus bases, o del Papa por encima de la propia Iglesia, son signos de privatización de la fe. Con la participación no se exacerban los problemas, sino que éstos encuentran solución; y, si no la hay, el propio acto participativo es la solución. La participación no puede hacerse primariamente instrumento ni objetivo ni arma ni argumento. Como el pez en el agua, así es la participación: su propio medio, su última razón, su esencial condición. Goza del privilegio singular de no necesitar utilidad ni consecuencia ni provecho ni rendimiento.

El entonces presidente de la Conferencia española, DÍAZ MERCHÁN, solicitaba en el Sínodo de Obispos que "se abrieran cauces a la participación real de todos los miembros de la Iglesia, ya que es cosa de todos»; de lo contrario, advertía la Conferencia del Canadá, «nuestras mentalidades, nuestras prácticas y nuestros discursos no concuerdan con las afirmaciones sobre la igualdad que se encuentran en nuestras declaraciones». El obispo de Macao, RODRÍGUEZ DA COSTA vaticinaba que, «mientras los laicos no tengan espacio en las decisiones que afectan a la fe y a la moral, pertenecerán a la Iglesia, pero no llegarán a ser Iglesia. Este Sínodo debe poner fin a un laicado viejo, pasivo y ciegamente obediente».

La participación hacia fuera la resumía el P. VIGANó en el imperativo de «formar un cristiano que, precisamente por serlo, es un cualificado y responsable ciudadano». Se solicitaba que el Sínodo profundizara las nociones de sensus fidei o sensus fidelium, ya que el Espíritu Santo actúa en todo el Pueblo de Dios». Es falso, en consecuencia, que «los pastores dirigen y los fieles obedecen», ya que ambos «deben ser obedientes al Espíritu Santo». El Cardenal DANNELS solicitaba que «el concepto de participación consultiva debe ser interpretado en el sentido más amplio posible». La Iglesia de Canadá (Rayes) proponía que el propio Sínodo «deje de ser una reunión de obispos y se transforme en un proceso sinodal que dé lugar a una amplia consulta a las Iglesias locales y permita a todos los bautizados e interesados participar activamente en la vida de la Iglesia universal». El concepto y la práctica de la sinodalidad se impuso como referente. La participación es ya inexcusable, como significaba el Cardenal DANNELS, «sobre todo en las materias que se sitúan en la frontera entre Iglesia y mundo bioética, doctrina social».

El uso público de la razón debe llevar a la Iglesia a estimar más de lo que actualmente lo hace las intervenciones colegiadas. Al modo y mane- 


\section{La dimensión pública de la fe}

ra como se produjeron un día en torno a la Humanae Vitae. Algunos episcopados hicieron un uso público de su derecho, y de este modo la recepción se fue haciendo en la perspectiva que abrían aquellas intervenciones, en lugar de hacerlo en la perspectiva abierta exclusivamente por la Casti Connubii. Esta cooperación colegial no sólo es esencial para el ejercicio público de la fe, sino «una verificación indispensable, incluso para el Papa, a la luz de la teología de la infalibilidad» (HÄRING: 221-222). Cuando se niega la importancia de este ejercicio colegial, se achican los espacios de la publicidad de la fe.

\section{Fe e interés público}

El carácter público de la fe se ilumina igualmente en el interior del dilema entre universal y particular. El interés público es el ámbito de lo generalizable y universalizable. El interés privado, por el contrario, evoca lo particular y excluyente. De este modo, al hablar del sector público de la economía queremos significar que está en función de un hipotético bien común. Mientras el sector privado busca elevar al máximo los beneficios propios, el sector público intenta generalizarlos. Al hablar del carácter público de la Administración, se quiere significar que debe evitar la discriminación en la prestación de servicios. De este modo, hablamos del erario público, de las empresas públicas o de la escuela pública en razón de un ámbito, que antepone los intereses generales a los particulares y se sustrae a los tratos discriminatorios.

Desde esta perspectiva, el espacio público, que ha sido caracterizado por el ejercicio de la comunicación, el debate y la participación, remite necesariamente a la voluntad de afrontar los problemas reales desde una perspectiva racional y a la búsqueda de soluciones conjuntas en términos universalizables y no excluyentes.

\section{La vinculación a la razón}

La tradición cristiana ha colaborado decisivamente en la elaboración del concepto de humanidad, que permite afirmar una igualdad de principio entre los seres humanos y reconocer una misma dignidad a través de una naturaleza humana universal independiente de la fe. Su grandeza consistió precisamente en establecer esta categoría en términos de universalidad, sobrepasando de este modo el espacio de una tradición particular. 
A través del concepto de «naturaleza humana» se intentó fundamentar lo universalizable y limitar los abusos del poder civil, una vez que históricamente no podía hacerse en clave eclesiástica. Se pudo garantizar así el derecho de los nuevos bárbaros contra los cristianos, sin que sirviera de pretexto la condición pagana, ya que su derecho se funda en la naturaleza, que es previa al orden de la gracia. Se pudo de este modo legitimar un nuevo sujeto histórico extracristiano y reconstruir sobre bases no cristianas la convivencia. La referencia a la «naturaleza humana» tuvo no sólo una significación ética, sino también política, ya que ninguna teorización cristiana sobre la gracia o sobre la fe podía anular su común condición (RUGGIERI: 163, nota 59).

La idea de humanidad sirvió para superar las dudas que llegaban del Nuevo Continente sobre la condición humana de los indios; para unir en una misma dignidad a los negros y a los blancos; para saldar en el mismo destino a Jesucristo y a los creyentes; para determinar la continuidad entre los pueblos primitivos y los supercivilizados; para deslegitimar la división entre esclavos y libres; para afirmar lo que tienen de común los esclavos y los libres, los creyentes y los ateos, los matemáticos y los poetas..., y todo ello sin renunciar a la diversidad y singularidad de cada persona, ya que la idea de humanidad es la categoría-marco que permite pensar la diferencia en el interior de una misma dignidad, que hace posible plantear la comunicación intercultural.

Permite garantizar la vocación universalizadora de la cultura, sin mengua de los factores diferenciales, tanto frente al totalitarismo de las unidades de destino superiores como frente al totalitarismo discriminador y excluyente de la tradición romántica del «Volksgeist».

La tradición cristiana atribuyó siempre a esta categoría un carácter común y reconocible, que en su mínimo contenido es coextensiva a toda la humanidad, posee un valor universal y afecta a todos los hombres de todos los tiempos y de todos los lugares. Se le atribuía igualmente la cognoscibilidad a través de la sola razón, de modo que «no podía ser ignorada por nadie verdaderamente hombre» (PIZZORNI: 101).

La adscripción de los hombres a la razón y a una condición comunes ha sido mantenida permanentemente por la tradición cristiana. Sólo en los últimos años ha pasado a cuestionarse en nombre de un fundamentalismo ingenuo y de un tradicionalismo engañoso.

Con frecuencia se busca hoy un fundamento social en Dios que nos permita defendernos de la Modernidad, inmunizarnos frente a la Ilustración y obstaculizar el proceso de secularización. La vida y la sociedad, los sistemas morales y las costumbres sociales son viables - dicen- sólo si

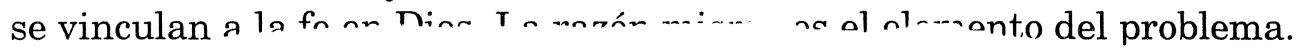


Según esta opinión, la posible emancipación de la razón respecto del factor religioso orienta el camino hacia la propia destrucción e invalida cualquier recurso a la razón como instancia de sentido y de legitimación.

Ahora bien, cuando el ejercicio de la razón se sustituye por la invocación a la fe, ésta se limita necesariamente a ser un hecho particular de los creyentes y las Iglesias se convierten inevitablemente en una institución entre otras.

Si la paz no es posible sin apelar a la fe, si la moral sólo se justifica en la apelación a Dios, si la vida sólo es viable cuando se sostiene en la convicción cristiana, tanto la paz como la vida se empequeñecen al emitir en un sólo código. Para quien crea que la convivencia humana sólo se sostiene a través de su Iglesia, el ejercicio de la convivencialidad se metaboliza en un sólo registro.

La argumentación de estos fundamentalistas y tradicionalistas se apoya en la posibilidad de mostrar una realidad inconsistente y una sociedad amenazada. Tratan de mostrar que, si lo humano se deja así mismo, sólo conoce la decadencia.

Cuando se afirma que sin un grupo cristiano el hombre «queda indefenso ante la industria cultural» (GuISSANI: 117), o que la Iglesia «está llamada a convertirse en la salvación de lo humano como en la época de las invasiones bárbaras» (GIUSSANI: 156), se banaliza el significado de la Iglesia y el de la industria cultural.

Pero hay que advertir que esta posición olvida que nuestro tiempo ha alumbrado las mayores conquistas sociales y los sistemas de protección más exigentes frente a las necesidades. ¿Quién puede afirmar con rigor que el corporativismo de los gremios medievales es superior al Estado de derecho consagrado únicamente en una supuesta época secularizada?

¿Acaso fue mayor la solidaridad en los tiempos llamados «religiosos», que conocieron guerras y cruzadas? Cuando se nos propone volver a la Edad Media para encontrar la más exigente civilización cristiana, ¿se es consciente de que fue entonces cuando Occidente conoció los mayores índices de mortalidad infantil?

Al declarar "ruinosa y decadente la ética civil de Occidente» (GIUSSANI: 150), se olvida que ha sido precisamente en sus entrañas donde han nacido y se han consolidado los derechos humanos, individuales y sociales, y donde se ha luchado con mayor convicción contra la indignidad política del hambre, el militarismo o la tortura.

Si se afirma que «el pueblo está hoy sometido política y culturalmente» (GIUSSANI: 150), habrá que indicar dónde podemos encontrar el lugar de la emancipación, y si éste consiente alguna nostalgia por fórmulas pasadas. ¿Podremos denigrar en términos absolutos la actual época no-re- 
ligiosa después de no haber sido capaces en el pasado de acabar con las guerras realizadas en nombre de la religión? No fueron precisamente los que fundamentaron la sociedad en Dios quienes lucharon con más convicción en contra de los fanatismos. Estos vientos han preparado las tempestades que hoy nos preocupan.

«La búsqueda de un fundamento social en Dios carece de pertinencia $y$, en consecuencia, de verdad en una sociedad moderna, a la vez que vehicula una concepción discutible de Dios», que se representa como un absoluto inmutable y se sostiene sobre una visión antropomórfica utilitaria (VALADIER: 131-132).

Una vez que se hace a Dios necesario, se abren las vías al ateísmo, ya que sirve para estabilizar el cosmos y la historia, en lugar de insinuarse en términos de gratuidad; se abren las vías al nihilismo, ya que se vacían de sustantividad los valores, en lugar de proclamarle en términos de sobreabundancia libre; se abren las vías a la irreligiosidad, ya que, en lugar de la plenitud, se le utiliza «para resolver aparentemente unos problemas insolubles, o para erguir una fuerza ante la impotencia humana» (BONHOEFFER: 162).

\section{Las zonas de frontera}

Las sociedades modernas se caracterizan por la complejidad que da al conocimiento la autoconciencia de los propios límites. Ni la contradicción ni la paradoja pueden comprenderse tan sólo como defectos del conocimiento, sino que adquieren a menudo el papel esencial de explorar la realidad. Cuando queremos buscar lo simple, nos encontramos con la simplificación. El pensamiento complejo no apunta a lo elemental, que, como reconoce MoRIN, se funda en la unidad simple y en el pensamiento claro, sino a lo radical, en donde aparecen incertidumbres y antinomias. La simplicidad de los análisis pasa por alto el relativismo cultural y la complejidad de los sistemas morales. «El reconocimiento de la complejidad requiere el recurso a un pensamiento complejo que pueda tratar la interdependencia, la multidimensionalidad y la paradoja» (MoRIN: 232, 412, 441).

Existe hoy una convicción profunda de «la necesidad de sumirse en el agua de la duda» (WITTGENSTEIN), de «ir a aquella parte en que la razón entra en peligro» (BACHELARD). Como decía HöLDERLIN, «allí donde está el peligro, crece también lo que salva».

El universo actual de la fe no parece transitar en esta dirección. En su lugar, está obsesionado en procurarse certezas y seguridades. La consecuencia más grave consiste en distanciarse de aquellos territorios 
abiertos, que exigen reflexiones nuevas e intuiciones distintas de orden antropológico sociológico y ético. Carecemos de investigaciones suficientes en el campo de la genética, de la ecología, de las formas de reproducción de la vida, para que se pueda, sin simplificar, pronunciar una palabra definitivamente válida.

Con las certezas y los saberes simplificados, abandonamos el camino de la búsqueda humilde. Asumir la complejidad significa reconocer la densidad de las relaciones y entramados históricos, leer los acontecimientos sin esquemas preconstituidos, dejarse inquietar en los prejuicios $\mathrm{y}$ en las certezas.

La realidad compleja obliga a valorar las propuestas provisionales frente a las soluciones totales y definitivas. La provisionalidad conjuga por igual la humildad y la búsqueda y exige muchas veces transitar por un camino intermedio entre el todo y la nada, que va concretando nuevas formas de presencia y valorando los largos plazos, sin caer en el escepticismo ni en la irresponsabilidad, ya que las propuestas provisionales son también creíbles.

Cuando se pierde la búsqueda humilde y la dignidad de la provisionalidad, se pierde aquella verdad que nace justo en la ladera misma de la frontera. Si la verdad limita con el error, la obsesión por evitar el error nos hace perder con frecuencia la posibilidad misma de explorar la verdad. Ambos tienen una frontera común. «Entre la verdad y el error no hay una tierra neutra o una zona desmilitarizada. Si alguien, en la investigación de la verdad, llega hasta su frontera, ciertamente estará más cerca del error, pero ha recuperado una buena parte de la verdad: precisamente aquella parte que está más en contacto con los problemas, con los interrogantes, con la vida. Renunciar a esa parte de verdad equivaldría a reducir la verdad a una pura teoría, que ya no nos serviría para vivir y una verdad así no le puede interesar al hombre» (ESPASA). Quizá sea éste el efecto perverso que golpea al pensamiento teológico hoy. Cuando buscamos por todos los medios salvar la ortodoxia de la fe, sólo podemos hacerlo al precio de la fe misma. No cabe duda de que esa zona estará minada de peligros, pero, ¿acaso hay un peligro superior a aquel que supondría quedarse sin la verdad que está en la frontera?

\section{El territorio del Estado}

El origen de la esfera pública ha sido históricamente inseparable del Estado moderno. «La construcción de las formas modernas del Estado no sólo permitió delimitar, por diferencia, lo que en adelante no pertenecía 
al ámbito público, sino que, en mayor medida, supuso la garantía y la salvaguarda de lo privado» (CHARTIER: 411).

El nuevo cometido del Estado, que interviene cada vez más en materias que durante mucho tiempo quedaron fuera de su alcance, es el factor decisivo para replantear el espacio público de la fe. Los límites de la esfera privada dependen, ante todo, del modo en que se halle constituida la autoridad pública que el Estado reivindica y ejerce. Lo privado es lo no estatal. Las mutaciones del Estado son las metamorfosis de lo privado (CASTAN: 24-25).

Asistimos en este momento a unas transformaciones del Estado que hacen sumamente compleja la realización de la dimensión pública del proyecto de vida evangélica y, consecuentemente, de la misión de la Iglesia. Se encuentra aquí el «experimentum crucis» de la cuestión. Ya no basta con distanciarse del nacional-catolicismo y sus derivados ni de la privatización de la fe y sus sucedáneos, sino que nos urge construir una presencia capaz de asumir con radicalidad las potencialidades del sistema democrático y, a la vez, distanciarse de sus ambigüedades.

Del Estado democrático no está todo dicho cuando se le representa como el nuevo Gulag o el viejo Moloch, o cuando se ve en la conquista de sus espacios la garantía última de la fecundidad de la fe (conquista de la legislación, de la televisión...). Ni es el mal por excelencia ni puede verse en él el becerro de oro sobre el que se asienta la posibilidad de la eficacia. El perfil de esa presencia incorporará la triple experiencia que sostiene al Estado moderno.

El espacio de la fe cobra toda su fuerza cuando se afirma y se vive como libertad frente al Estado. «El cristianismo proclamó la distinción entre la condición de miembro de la sociedad política y la condición de creyente. Ante la pretensión de los gobernantes de Roma de que todos sus súbditos practicaran el culto al Emperador, para reforzar la unidad política del imperio, la Iglesia naciente opuso una rotunda negativa. No era lícito exigir, como prueba de fidelidad política, unas prácticas religiosas contrarias a las convicciones de algunos ciudadanos» (BELDA: 54).

El cristiano encuentra razones suficientes en su propia tradición para reclamar, exigir y fomentar la distinción entre ambos territorios. Cuando se hace de la fe católica un ingrediente esencial de la unidad política de una nación, se vulnera un principio fundamental de la tradición cristiana; cuando se achican los espacios de libertad, se tambalean los fundamentos del universo cristiano. Ciertamente que en la patología del Estado moderno hay una concentración del poder que alimenta su discurso y su práctica, sus tiranías y sus despotismos. La concentración del poder produce una especie de divinización y una hipertrofia de otras realidades 
humanas. En este sentido, es necesario que el Estado encuentre su límite en la moral y el derecho; y que se rehabiliten espacios fuera del Estado (sociedad civil, asociacionismo...). El cristiano ha de hacer la experiencia de la insobornable libertad frente al Estado. La dualidad sociedad-Estado posee una función humanizadora.

La segunda experiencia básica gira en torno a la libertad en el interior del Estado. El cristiano sabe que es portador de una dignidad que se expresa en el reconocimiento del valor absoluto de toda persona. Este es el límite de toda organización social, de todo poder -sea cual sea la índole de su procedencia- y, en consecuencia, del Estado. En nombre de esta dignidad, el cristiano experimentará con frecuencia la resistencia en el interior del Estado, que, como todo poder, posee una dinámica inmoderada y expansiva. El Estado y sus aparatos han de saber que en el interior de cada uno de nosotros hay una palabra que se hace afirmación absoluta, ajena a la transacción y al pacto, y que nadie tiene derecho a poner en duda ni a limitar su expresión. Sin esta libertad, las pretensiones de la subjetividad serían ilusorias. El espacio de la fe se sustrae al territorio administrado. El valor de esta contraposición cobra toda su fuerza allí donde el Estado pretende dirigir la totalidad de la existencia humana, pues la fe es necesariamente una fuerza que se opone a las imposiciones colectivas. Como Iglesia, siempre será el no-Estado y considerará intolerable cualquier intrusión en un terreno que es ajeno a la jurisdicción estatal. «La libertad de la Iglesia es el principio fundamental en las relaciones de la Iglesia con los poderes públicos» (Dignitatis $\mathrm{Hu}$ manae, 13). La comunidad de fe se afianza en el distanciamiento del Estado, hasta constituirse en una «libertad sagrada».El cristiano tiene razones suficientes para ser un hombre de conciencia, ejercer la ciudadanía y dejar de ser simple ejecutor o mandatario.

La tercera experiencia constitutiva de la presencia pública es la $l i$ bertad a través del Estado, que no es sólo ni primariamente un poder despótico, burocrático y policial, sino que es también «la organización de una comunidad histórica que le hace capaz de tomar decisiones» (WEIL). Una comunidad organizada en Estado articula las instituciones, funciones y papeles sociales en un espacio orgánico. y es esta articulación y organización lo que hace de la comunidad histórica un todo orgánico que "posibilita una práctica racional» (RICOEUR: 399). En este sentido, el Estado obstaculiza el abuso de poder, garantiza mayores cotas de igualdad y de libertad, monopoliza la violencia legítima, evitando su diseminación por el cuerpo social, y regula el uso de la fuerza. Lejos de ser represión y opresión, es una esfera de derecho que limita su arbitrariedad y posibilita la redistribución de los beneficios. 
Si las cosas son así, no está justificada la indigestión de Estado que ciertos católicos comparten con los neoliberales. Se han hecho tan familiares que parece necesario que el católico defienda la quiebra del Estado y actúe con dinámica de empresario privado. El Estado como espacio público es para ambos sinónimo de mal funcionamiento, peor gestor y pésimo prestador de servicios. Encarna todas las miserias y frente a él sólo se puede ser un sufrido ciudadano. En este discurso no está en juego la extralimitación de los poderes públicos, sino la incomprensión radical ante la creación moderna del Estado como redistribuidor.

\section{Bibliografía citada}

Álvarez Bolado, A.: “Compromiso terrestre y crisis de fe», en Vida cristiana y compromiso terrestre, Mensajero, Bilbao 1970.

ARIES, Ph.: «Para una historia de la vida privada», en Historia de la vida privada. III: Del Renacimiento a la Ilustración, Taurus, Madrid 1989.

Atanasio: De incarnatione Verbi, en Cerfs, París (Sources Chrétiennes 199).

BAHRO, R.: Cambio de sentido. Ed. HOAC, Madrid 1986.

BELDA, R.: «Entre la nostalgia del Nacional-Catolicismo y la privatización de la fe», en $M i$ sión abierta 2/1981.

- Los cristianos en la vida pública, DDB, Bilbao 1987.

BethGe, E.: Dietrich Bonhöffer. Teólogo, cristiano actual. DDB, Bilbao 1970.

BobBio, N.: Estado, gobierno, sociedad. Contribución a una teoría general de la política, Plaza y Janés, Barcelona 1987.

BonhomfFer, D.: Resistencia y sumisión, Ariel, Barcelona 1969.

CASTAN, N.: "Lo público y lo particular», en Historia de la vida privada. III: Del Renacimiento a la Ilustración, Taurus 1989.

CASTAN, N.; Lebrun, F.; Chartier: «Figuras de la modernidad», en Historia de la vida privada. III: Del Renacimiento a la Ilustración, Taurus, Madrid 1989.

Congar, Y.: "Ecclesia ab Abel», en Abhandlungen über Theologie und Kirche, Düsseldorf 1952.

- La Iglesia como Pueblo de Dios", en Concilium 1 (1965).

Denaux, A.: "L'Église comme communion», en Nouvelle Revue Théologique 110 (1988).

Documentos del Sínodo de Laicos 1987:

- Relación Introductoria - Proposiciones

- Mensaje de los Padres sinodales al Pueblo de Dios

Duby, G., Prefacio a la Historia de la vida privada I, Taurus, Madrid, 1989.

FEIL, E.: Die Theologie Dietrich Bonhöffers. Hermeneutik. Christologie. Weltverstiindnis, Kaiser, München 1971.

FORTE, B.: La teologia como compagnia, memoria e profezia, Paoline, Torino 1987.

GADAmer, H. G. Philosophische Lehrjahre, Klostermann, Frankfurt a.M. 1977.

GARCíA, M.: «La declaración sobre libertad religiosa», en El Concilio del siglo XXI, PPC, Madrid 1987.

GARCÍA ROCA, J.: «ltinerarios laicales. Consideraciones inactuales sobre el Sínodo de Laicos», en Iglesia Viva 137 (1988). 


\section{La dimensión pública de la fe}

- «Iglesia, acontecimiento de liberación», en El Concilio del siglo XXI, PPC, Madrid 1987.

- ¿¿Presencia o mediación? Dos modos de entender el compromiso cristiano en el mundo", en Sal Terrae 74/9 (1986).

— «Presencia de los cristianos en el mundo», en Misión Abierta 2/1985.

GINER, S.: "Avatares de la sociedad civil», en Arbor 494 (1987).

GÓMEZ CAFFARENA, J.: «Conciencia crítica y moderna y autocrítica cristiana», en Misión Abierta $1 / 1980$.

GiUSSANI, L.: El movimiento de Comunión y Liberación, Encuentro, Madrid 1987.

GOFFMAN, E.: La presentación de la persona en la vida cotidiana, Amorrortu, Buenos Aires 1971.

Guerau, F.: La vida pedagógica, Roselló, Barcelona 1985.

HÄERING, B.: Fede, Storia, Morale. Intervista di Gianni Licheri, Borla, Roma 1989.

Heller, A.: Sociología de la vida cotidiana, Península, Barcelona 1977.

KASPER, W.: "Vocazione e missione del laico nella Chiesa e nel mondo", en Humanitas 5 (1987).

Koening, F.: Iglesia, ¿adónde vas?, Sal Terrae, Santander 1986.

LAPASSADE, G.: Grupos, organizaciones e instituciones. La transformación de la burocracia, Gedisa, Barcelona 1985.

LEBRUN, F.: "Las reformas: devociones comunitarias y piedad personal», en Historia de la vida privada. III: Del Renacimiento a la Ilustración, Taurus, Madrid 1989.

LE GoFf, J.: Lo maravilloso y lo cotidiano en el Occidente medieval, Gedisa, Barcelona 1985.,

Lipovetsky, G.: La era del vacío, Anagrama, Barcelona 1986.

Morin, E.: La Méthode (1). La connaissance de la connaissance, Seuil, Paris 1986.

ORTEGa y Gasset, J.: Sobre la razón histórica, Alianza Editorial, Madrid 1970.

Pizzonni, R.: Attualitti del diritto naturale?, Lateranense, Roma 1971.

RATZINGER, J.: Informe sobre la fe, BAC, Madrid 1985.

RICoeur, P.: Du texte à I' action. Essais d' herméneutique,II, Seuil, Paris 1986.

RizzI, A.: El mesianismo en la vida cotidiana, Herder, Barcelona 1986.

ROVIRA, J. M.: «Sociedad perfecta y sacramentum salutis: dos conceptos eclesiológicos, dos imágenes de la Iglesia», en Iglesia y sociedad en España 1939-1945, Madrid 1977.

- Fe y cultura en nuestro tiempo, Sal Terrae, Santander 1988.

RugGieRI, G.: La compagnia della fede. Linee di teologia fondamentale, Marietti, Torino 1980.

Ruiz DE la Peña, J. L.: Teología de la creación, Sal Terrae, Santander 1986.

SANCHís, A.: Hacia una ética de la autonomía personal, Facultad de Teología «San Vicente Ferrer», Valencia 1982.

TOURAIne, A.: El post socialismo, Planeta, Barcelona 1980.

URBINA, F.: "Hacia una nueva figura pública de la Iglesia en España», en Misión Abierta $1 / 1979$.

VAlADIER, P.: L'Église en procès. Catholicisme et société moderne, Calman-Levy, Paris 1987.

Wolf, M.: Sociologías de la vida cotidiana, Cátedra, Madrid 1982.

ZAHRNT, H.: A vueltas con Dios. La teología protestante en el siglo XX, Hechos y Dichos, Zaragoza 1972. 